\title{
ON ERGODIC THEOREM FOR A FAMILY OF OPERATORS
}

\author{
Abdellah Akrym, Abdeslam El BaKkali* and AbDelkhalek Faouzi
}

Abstract. In this paper, we obtain a generalization of the uniform ergodic theorem to the family of bounded linear operators on a Banach space. We present some elementary results in this setting and we show that Lin's theorem can be extended from the case of a bounded linear operator to the case of a family of bounded linear operators acting on a Banach space.

Mathematics subject classification (2020): 37Axx, 47A35, 47AXX.

Keywords and phrases: Cesàro mean operator, family of operators, ergodic theorem.

\section{REFERENCES}

[1] M. J. Beltrán, M. C. Gómez-Collado, E. Jordá And D. Jornet, Mean ergodic composition operators on Banach spaces of holomorphic functions, J. Funct. Anal. 270, (2016), 4369-4385.

[2] Y. DeRRIENNIC, On the mean ergodic theorem for Cesàro bounded operators, Colloquium Math. 84/85, 2 (2000), 443-445.

[3] N. Dunford, Spectral theory I. Convergence to projection, Trans. Amer. Math. Soc. 54, (1943), $185-217$.

[4] R. EMiLion, Mean bounded operators and mean ergodic theorems, J. Funct. Anal. 61, (1985), 1-14.

[5] E. Hille, Remarks on ergodic theorems, Trans. Amer. Math. Soc. 57, (1945), 246-269.

[6] M. Krishna K, P. S. Johnson, Quotient Operators and the Open Mapping Theorem, Filomat 32, 18 (2018), 6221-6227.

[7] H. LI, Equivalent conditions for the convergence of a sequence $\left\{B^{n}\right\}_{n=1}^{\infty}$, Acta Math. Sinica 29, (1986), 285-288.

[8] M. Lin, On the uniform ergodic theorem, Proc. Amer. Math. Soc. 43, 2 (1974), 337-340.

[9] M. Lin, On the uniform ergodic theorem, II, Proc. Amer. Math. Soc. 46, 2 (1974), 217-225.

[10] S. Macovei, Spectrum of a Family of Operators, Surv. Math. Appl. 6, (2011), 137-159.

[11] S. MACOvei, Local Spectrum of a Family of Operators, Ann. Funct. Anal. 4, 2 (2013), 131-143.

[12] M. MbekhtA And J. Zemánek, Sur le théorème ergodique uniforme et le spectre, C. R. Acad. Sci. Paris série I Math. 317, 1 (1993), 1155-1158. 